\title{
Intraoperative BOLD-fMRI Cerebrovascular Reactivity Assessment
}

\author{
Giovanni Muscas, Christiaan Hendrik Bas van Niftrik, \\ Martina Sebök, Giuseppe Esposito, Luca Regli, \\ and Jorn Fierstra
}

\section{Introduction}

Cerebrovascular reactivity (CVR) is the physiological capacity of the brain vessels to modulate cerebral blood flow (CBF) by changing their caliber in response to a vasoactive stimulus: this allows an adequate supply of oxygenated blood to the brain despite wide variations of perfusion pressure $[1,2]$.

Diverse neurological diseases can strain this physiological capacity beyond a limit that the brain vessels cannot further compensate, leading to exhaustion of the cerebrovascular reserve and, therefore, to CVR impairment [3]. Impaired CVR can be used as a measure of the hemodynamic stress the brain is undergoing in a particular anatomical area. Many studies have confirmed the validity of CVR as a marker of the hemodynamic state in vascular diseases [4-9]. The clinical relevance of CVR in predicting stroke risk has been confirmed, and CVR is widely investigated with different techniques, allowing risk stratification and providing valuable information for therapeutic decision-making $[9,10]$. We have recently proposed and tested an intraoperative CVR assessment to obtain early information that could potentially help during the surgical procedure $[11,12]$.

G. Muscas

Department of Neurosurgery, University Hospital Zurich,

Zurich, Switzerland

Department of Neurosurgery, Careggi University Hospital, Florence, Italy

Clinical Neuroscience Center, University of Zurich,

Zurich, Switzerland

C. H. B. van Niftrik · M. Sebök · G. Esposito · L. Regli

J. Fierstra $(\bowtie)$

Department of Neurosurgery, University Hospital Zurich,

Zurich, Switzerland

Clinical Neuroscience Center, University of Zurich,

Zurich, Switzerland

e-mail: vanniftrik@usz.zch; martina.seboek@usz.ch;

giuseppe.esposito@usz.ch; luca.regli@usz.ch; jorn.fierstra@usz.ch
CVR can be studied by applying a vasoactive stimulus to a patient and measuring the resulting changes at the brain level, either by CBF modifications or by surrogate of blood flow. As vasoactive stimulus, drugs or endogenous substances like $\mathrm{CO}_{2}$ can be used [1]. Variations in the arterial $\mathrm{CO}_{2}$ concentrations are obtainable by induced or voluntary apnea $[1,13]$. To measure hemodynamic changes after administration of a vasoactive stimulus, many methods are granted, like Doppler sonography [9], arterial spin labeling (ASL) [14], or blood oxygenation-level dependent functional magnetic resonance imaging (BOLD-CVR) [3]. Detecting changes in the BOLD signal has proved a valid method with high imaging resolution, allowing a good depiction of the hemodynamic state at brain tissue level. This exploits deoxyhemoglobin paramagnetic properties, which make the BOLD signal get lower with higher blood deoxyhemoglobin concentrations $[1,15]$. Areas with a higher blood flow achieve a higher deoxyhemoglobin clearance, thereby displaying a higher oxyhemoglobin/ deoxyhemoglobin ratio, which ultimately results in higher BOLD signal [1].

\section{Materials and Methods}

This study has been approved by the cantonal ethics board of the Canton of Zurich, Switzerland (KEK-ZH-Nr. 2012-0427) and all participants signed informed consent prior to the study. An attempt to measure BOLD-CVR intraoperatively was first accomplished in oncological patients [11, 12]. Considering the technical issues associated with obtaining controlled iso-oxic hypercapnic stimuli and the need of a cooperative patient for this purpose [1], only breath-holding tasks were feasible so far to obtain $\mathrm{CO}_{2}$ raises in unconscious patients. In the operating setting, a sedated and intubated patient is transferred from the operating theater to the adjacent MR suite, following a previously described protocol used at our institution $[11,16]$ and scanned on a 3-tesla device, obtaining BOLD, T1-weighted without contrast enhancement, plus other sequences according 


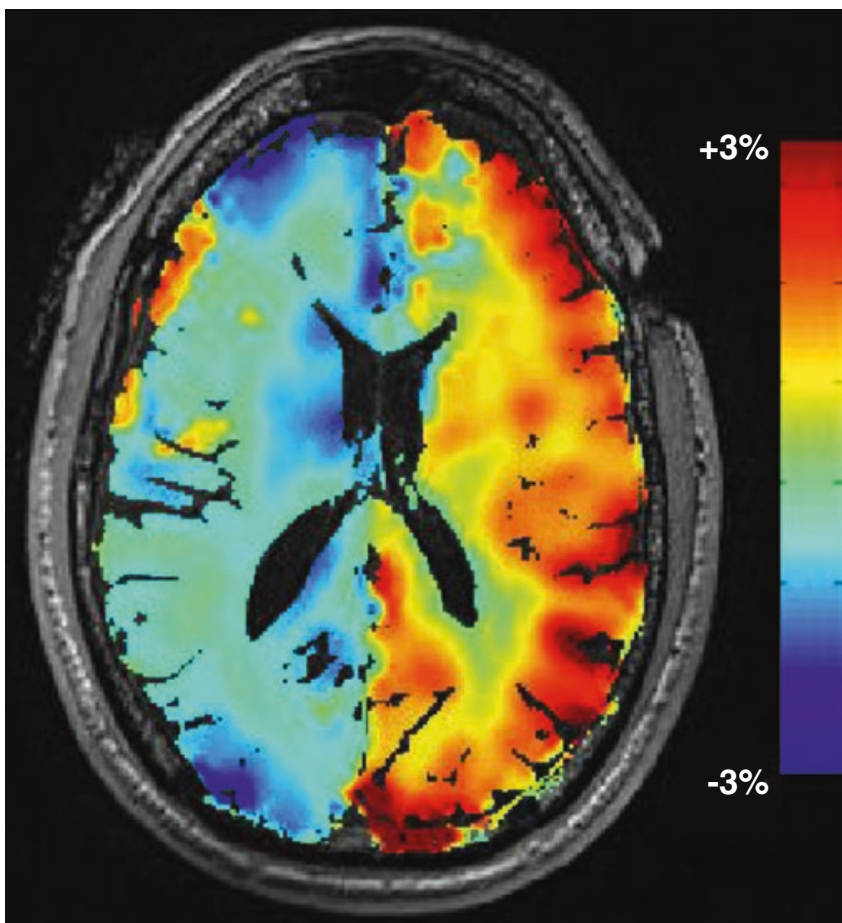

Fig. 1 Example of intraoperative BOLD-CVR color-coded map. Intraoperative BOLD-CVR assessment in a patient with occlusion of the right internal carotid artery after STA-MCA bypass for flowaugmentation. Areas with impaired hemodynamic status are depicted in blue. The color scale refers to the mean percentage change in BOLD signal per voxel between baseline and hypercapnic state to the specific patient's case (i.e., T1-weighted with contrast, $\mathrm{T} 2$-weighted, fluid attenuation inversion recovery [FLAIR] and susceptibility weighted $[\mathrm{SWI}]$ sequences for tumor patients, TOF-MRA or diffusion weighted imaging [DWI] in vascular diseases). The technical details about acquisition parameters can be found in our previous publications $[11,12,17]$. During acquisition of the BOLD sequences, hypercapnia is induced by three 44-s apnea cycles obtained by halting the ventilator, followed by hyperventilation to return to the subject's baseline $\mathrm{CO}_{2}$. Between each hypercapnic challenge, an 88-s baseline $\mathrm{CO}_{2}$ period is maintained. This allows obtaining satisfactory $\mathrm{CO}_{2}$ oscillations and therefore adequate vasoactive stimuli resulting in coherent BOLD-signal fluctuations [11].

Pre-processing and data analysis are performed following a method described previously [11, 18, 19]. CVR can be thus calculated on a voxel-by-voxel basis and measured as the mean percentage BOLD signal change between baseline and hypercapnia. For optimal depiction, the percentage changes values are color-coded and overlaid on the T1-wighted anatomical scan acquired during the same session (see Fig. 1).

\section{Results}

The intraoperative BOLD-CVR assessment was performed at our institution on both oncological and vascular diseases $[11,12,17,20]$ (Table 1). In a first attempt to assess its fea-

Table 1 Patient sex, age, diagnosis and intraoperative CVR values of all the patients undergoing intraoperative BOLD-CVR assessment included in previous studies

\begin{tabular}{|c|c|c|c|c|c|}
\hline Sex/age & Diagnosis & $\begin{array}{l}\text { CVR values whole } \\
\text { brain }\end{array}$ & $\begin{array}{l}\text { Affected } \\
\text { hemisphere }\end{array}$ & $\begin{array}{l}\text { Unaffected } \\
\text { hemisphere }\end{array}$ & $\begin{array}{l}\text { Difference affected vs. } \\
\text { unaffected }\end{array}$ \\
\hline 1. M 43 & $\begin{array}{l}\text { Anaplastic astrocytoma (grade III } \\
\text { WHO) }\end{array}$ & 0.9 & 1.18 & 0.94 & $125.5 \%$ \\
\hline 2. M 31 & Oligoastrocytoma (grade III WHO) & 0.13 & 0.83 & 0.18 & $461.1 \%$ \\
\hline 3. M 18 & Inconclusive & 1.12 & 1.24 & 1.05 & $118.1 \%$ \\
\hline 4. M 51 & Glioblastoma (grade IV WHO) & 1.01 & 1.02 & 0.8 & $127.5 \%$ \\
\hline 5. F 41 & $\begin{array}{l}\text { Anaplastic astrocytoma (grade III } \\
\text { WHO) }\end{array}$ & 0.95 & 1.01 & 0.89 & $113.5 \%$ \\
\hline 6. M 38 & $\begin{array}{l}\text { Anaplastic oligoastrocytoma (grade III } \\
\text { WHO) }\end{array}$ & 0.85 & 0.1 & 0.69 & $14.5 \%$ \\
\hline 7. M 18 & Medulloblastoma & 0.14 & 1.37 & 0.19 & $721.1 \%$ \\
\hline 8. M 46 & Morbus Biswanger & 1.35 & 0.48 & 1.33 & $36.1 \%$ \\
\hline 9. M 76 & 3-vessel atherosclerosis & 0.43 & 0.42 & 0.38 & $110.5 \%$ \\
\hline 10. F 42 & Intravasal and mural myxomas & 0.4 & 0.72 & 0.37 & $194.6 \%$ \\
\hline 11. F 68 & ICA occlusion & 1.4 & 1 & 1.95 & $51.3 \%$ \\
\hline 12. F 66 & ICA occlusion & 2.08 & 1.54 & 2.61 & $59.0 \%$ \\
\hline 13. F 49 & Moyamoya disease & 1.44 & 1.64 & 1.22 & $134.4 \%$ \\
\hline 14. F 62 & ICA, MCA ans ACA occlusion & 0.16 & 0.03 & 0.28 & $10.7 \%$ \\
\hline 15. M 50 & ICA occlusion & 0.76 & 0.71 & 0.81 & $87.7 \%$ \\
\hline 16. F 46 & $\begin{array}{l}\text { Anaplastic astrocytoma (grade III } \\
\text { WHO) }\end{array}$ & 1.77 & 1.62 & 1.83 & $88.5 \%$ \\
\hline
\end{tabular}

CVR values are calculated as mean \% BOLD signal change between baseline and the hypercapnic (breath-hold) challenge 
sibility, ten patients (two with vascular diseases and eight with oncological diseases) who were scheduled to undergo an intraoperative MR assessment to assess extent of resection in tumor cases or bypass anastomosis in STA-MCA revascularization surgery for flow augmentation were also scanned as described above with a BOLD scan.

As a preliminary finding, none of the patients displayed intra- or postoperative complications due to the prolonged time for anesthesia or for the breath-hold task. Analyzing CVR data showed impaired values for oncologic patients within the lesion and on both hemispheres [17]. We then scanned more patients and obtained a small cohort of five patients with high-grade gliomas. Interestingly, they showed a lower CVR in brain areas that showed tumor recurrence on follow-up [12].

In patients undergoing STA-MCA flow augmentation bypass surgery, intraoperative CVR values were on average higher after revascularization [20] and again, none of them had peri- or postoperative complications.

\section{Discussion}

The aim of introducing and developing BOLD-CVR assessment is to offer a new tool, which could help surgery and influence decision-making by offering an early feedback on the hemodynamic state of the brain. To this aim, further studies with larger cohorts and long follow-up are still needed. BOLD-CVR could be useful in discriminating normal brain from tumor tissue beyond the limits of current standards, like T1-weighted imaging with contrast enhancement [21] and, if future studies confirmed our preliminary results, offer a better depiction of areas of tumor infiltration. This information, if gained intraoperatively, could be helpful to achieve a better extent of resection. It is important to stress, however, that BOLD signal is not a measure of CBF alone, being that it is dependent on other physiological parameters such as cerebral blood volume (CBV), hematocrit, and cerebral metabolic rate of oxygen $\left(\mathrm{CMRO}_{2}\right.$ consumption [15, 22]. More precisely, CVR is a measure of the vessels' ability to modulate blood flow [2]. As mentioned previously, cerebrovascular reserve can be exhausted in some areas undergoing relevant hemodynamic stress. In these areas, a vasoactive stimulus produces a "steal" blood flow to areas with consumed reserve capacity to others with preserved CVR [23]. This is depicted by a lower BOLD-signal in areas with exhausted capacity [3].

In patients undergoing STA-MCA bypass revascularization for flow augmentation (for example in Moymoya disease), an immediate intraoperative feedback on the brain hemodynamic state after the microanastomosis could prove its efficacy in actually revascularizing the hypoperfused areas of the brain by depicting early CVR improvements, if present [20]. This information could also help in the operative decision-making process and to estimate the success of the bypass.

Despite these promising possibilities, this type of information is currently not available. First, the technique associated with the vasoactive stimulus (i.e., breath-holding) has inherent limitations that impede a precise comparison between data. Specifically, breath-holding allows for a raise in $\mathrm{CO}_{2}$ arterial concentration, but since it also causes concomitant hypoxia, it can alter the cellular metabolism and therefore also the $\mathrm{CO}_{2}$ production [1]. Moreover, breathholding allows for a raise in the $\mathrm{CO}_{2}$ arterial concentration, which varies between subjects according to each subject's features and physiologic parameters (age, sex, weight, metabolic status, and physical fitness) and in the same subject over time [1]. The entity of this change is therefore unpredictable, and the vasoactive stimulus cannot be controlled or modulated [1], thereby providing different entities of vasoactive stimulus in different investigations. This hinders interand intrasubject comparisons. These limitations are avoided by using a custom gas blender (Respiract ${ }^{\mathrm{TM}}$, Thornhill Medical, Toronto, Canada), which allows acquisition of targeted hysoxic pseudo-square waved changes of arterial $\mathrm{CO}_{2}$ concentration: a controlled and consistent stimulus can be provided by letting the subject inhale and rebreathe a gas mixture to obtain $10 \mathrm{mmHg}$ raises of the $\mathrm{CO}_{2}$ arterial concentration from the previously registered subject's baseline $[1,3]$ (Fig. 2). Nevertheless, this has technical nuisances that hinder its intraoperative employment. With the future improvements of currently used technologies [10, 24] to obtain controlled changes of the inhaled $\mathrm{CO}_{2}$ concentration, we expect to be able to perform BOLD-CVR investigations with controlled vasoactive stimuli also intraoperatively in the near future. In our experience, this also impeded a direct quantitative comparison between intra- and pre- or postoperative scans, since these were acquired with different techniques (see also van Niftrik and Piccirelli [18, 19] for further technical details on the techniques and data analysis).

Secondly, we dealt with cohorts with limited numbers, which therefore does not allow us to extend our conclusions to other patients.

Nevertheless, intraoperative BOLD-CVR assessment offered interesting results, which we think deserve further investigation: first, we observed an early intraoperative change after revascularization in patients undergoing bypass revascularization surgery for flow augmentation with BOLDCVR. Second, we identified an association with intraoperative findings and the evolution of the disease. Third, we confirmed that this assessment is not associated with higher complication rates. All these findings offer, in our opinion, a reasonable basis for further investigations.

Further developments of this application will include patients with aneurysmal subarachnoid hemorrhage. 


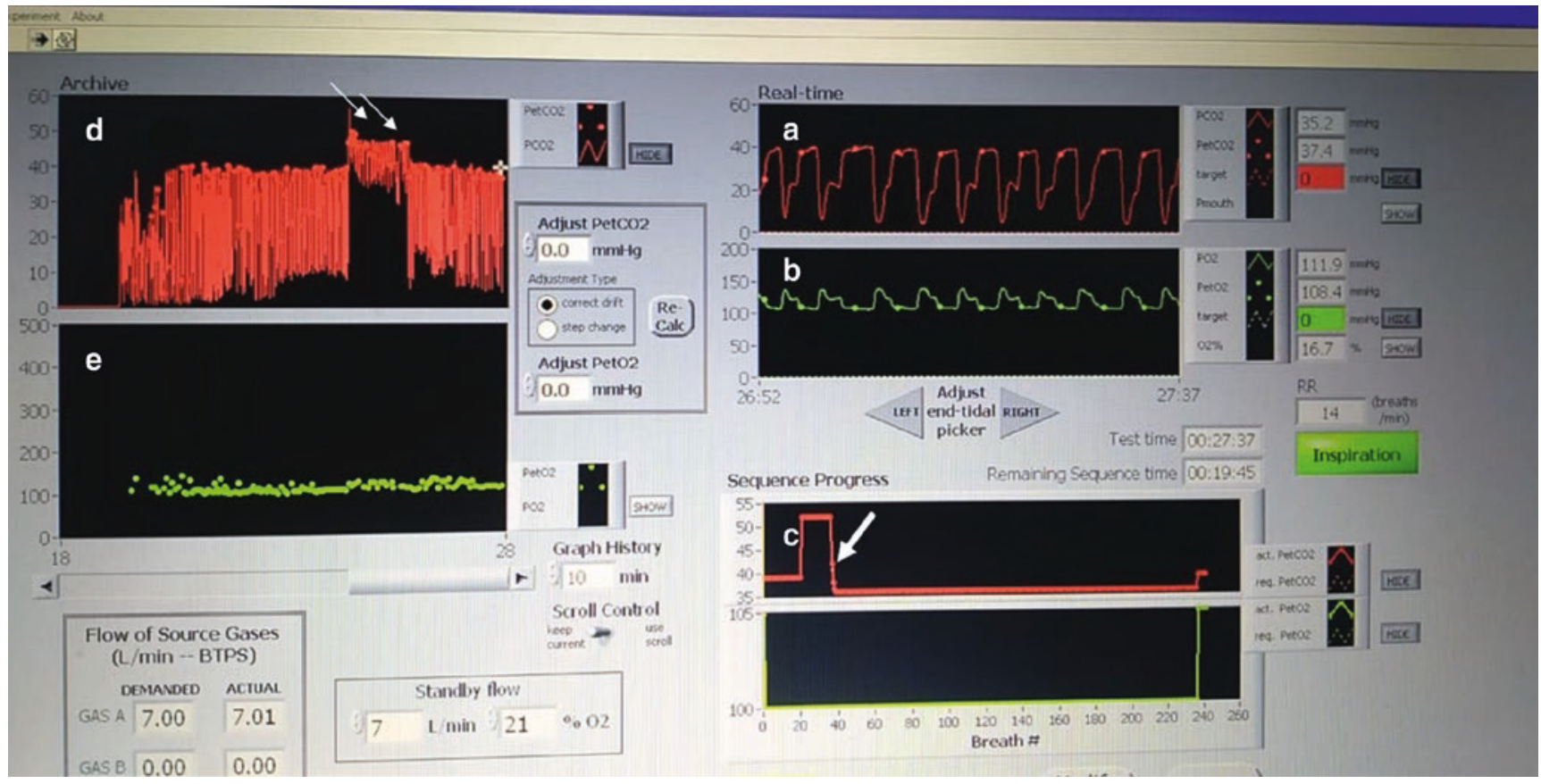

Fig. 2 Interface of the custom gas blender (Respiract ${ }^{\mathrm{TM}}$, Thornhill Medical, Toronto, Canada). This allows providing controlled hypercapnic stimuli of $10 \mathrm{mmHg} \mathrm{CO}$ concentration raises and cannot be currently used intraoperatively due to hardware nuisances. Future developments of this techniques will allow to employ it also in an intraoperative setting. (a: breath-by-breath registered subject's $\mathrm{CO}_{2}$ concentration and $\mathbf{b}$ : $\mathrm{O}_{2}$ concentration; $\mathbf{c}$ : targeted $\mathrm{CO}_{2}$ concentration during

Specifically, impaired CVR has been found after aneurysmal subarachnoid hemorrhage (SAH) in patients with lower clinical grade, and progressive impairment of CVR was associated with a higher risk of delayed cerebral ischemia (DCI) [25]. The purpose of obtaining an intraoperative or ultraearly BOLD-CVR assessment would be to identify areas with impaired CVR at risk for DCI or to assess a CVR value for future comparison for follow-up, in order to predict DCI.

\section{References}

1. Fierstra J, Sobczyk O, Battisti-Charbonney A, Mandell DM, Poublanc J, Crawley AP, Mikulis DJ, Duffin J, Fisher JA (2013) Measuring cerebrovascular reactivity: what stimulus to use? J Physiol 591:5809-5821. https://doi.org/10.1113/ jphysiol.2013.259150

2. Sam K, Poublanc J, Sobczyk O, Han JS, Battisti-Charbonney A, Mandell DM, Tymianski M, Crawley AP, Fisher JA, Mikulis DJ (2015) Assessing the effect of unilateral cerebral revascularisation on the vascular reactivity of the non-intervened hemisphere: a retrospective observational study. BMJ Open 5:e006014. https://doi. org/10.1136/bmjopen-2014-006014

3. Fisher JA, Venkatraghavan L, Mikulis DJ (2018) Magnetic resonance imaging-based cerebrovascular reactivity and hemodynamic reserve: a review of method optimization and data interpretation. Stroke. https://doi.org/10.1161/strokeaha.118.021012 the exam: a $10 \mathrm{mmHg}$ increase in $\mathrm{CO}_{2}$ concentration of the inhaled gas is provided to the patient [arrow]; $\mathbf{d}$ : subject's $\mathrm{CO}_{2}$ concentration registered during the exam $-10 \mathrm{mmHg} \mathrm{CO}_{2}$ pseudo-square raises are obtained [double arrow], providing a valid vasoactive stimulus; e: subject's $\mathrm{O}_{2}$ concentration during the exam-note that the concentration remains stable during the whole exam)

4. Blair GW, Doubal FN, Thrippleton MJ, Marshall I, Wardlaw JM (2016) Magnetic resonance imaging for assessment of cerebrovascular reactivity in cerebral small vessel disease: a systematic review. J Cereb Blood Flow Metab 36:833-841. https://doi.org/10. 1177/0271678X16631756

5. Cogswell PM, Davis TL, Strother MK, Faraco CC, Scott AO, Jordan LC, Fusco MR, Frederick BD, Hendrikse J, Donahue MJ (2017) Impact of vessel wall lesions and vascular stenoses on cerebrovascular reactivity in patients with intracranial stenotic disease. J Magn Reson Imaging 46:1167-1176. https://doi.org/10.1002/ jmri.25602

6. Conklin J, Fierstra J, Crawley AP, Han JS, Poublanc J, Mandell DM, Silver FL, Tymianski M, Fisher JA, Mikulis DJ (2010) Impaired cerebrovascular reactivity with steal phenomenon is associated with increased diffusion in white matter of patients with Moyamoya disease. Stroke 41:1610-1616. https://doi.org/10.1161/ STROKEAHA. 110.579540

7. Conklin J, Fierstra J, Crawley AP, Han JS, Poublanc J, Silver FL, Tymianski M, Fisher JA, Mandell DM, Mikulis DJ (2011) Mapping white matter diffusion and cerebrovascular reactivity in carotid occlusive disease. Neurology 77:431-438. https://doi.org/10.1212/ WNL.0b013e318227b1e7

8. Mandell DM, Han JS, Poublanc J, Crawley AP, Fierstra J, Tymianski M, Fisher JA, Mikulis DJ (2011) Quantitative measurement of cerebrovascular reactivity by blood oxygen level-dependent MR imaging in patients with intracranial stenosis: preoperative cerebrovascular reactivity predicts the effect of extracranial-intracranial bypass surgery. AJNR Am J Neuroradiol 32:721-727. https://doi. org/10.3174/ajnr.A2365 
9. Silvestrini M, Vernieri F, Pasqualetti P, Matteis M, Passarelli F, Troisi E, Caltagirone C (2000) Impaired cerebral vasoreactivity and risk of stroke in patients with asymptomatic carotid artery stenosis. JAMA 283:2122-2127

10. Ellis MJ, Ryner LN, Sobczyk O, Fierstra J, Mikulis DJ, Fisher JA, Duffin J, Mutch WA (2016) Neuroimaging assessment of cerebrovascular reactivity in concussion: current concepts, methodological considerations, and review of the literature. Front Neurol 7:61. https://doi.org/10.3389/fneur.2016.00061

11. Fierstra J, Burkhardt JK, van Niftrik CH, Piccirelli M, Pangalu A, Kocian R, Neidert MC, Valavanis A, Regli L, Bozinov O (2017) Blood oxygen-level dependent functional assessment of cerebrovascular reactivity: feasibility for intraoperative 3 Tesla MRI. Magn Reson Med 77:806-813. https://doi.org/10.1002/mrm.26135

12. Fierstra J, van Niftrik B, Piccirelli M, Burkhardt JK, Pangalu A, Kocian R, Valavanis A, Weller M, Regli L, Bozinov O (2016) Altered intraoperative cerebrovascular reactivity in brain areas of high-grade glioma recurrence. Magn Reson Imaging 34:803-808. https://doi.org/10.1016/j.mri.2016.02.003

13. Urback AL, MacIntosh BJ, Goldstein BI (2017) Cerebrovascular reactivity measured by functional magnetic resonance imaging during breath-hold challenge: a systematic review. Neurosci Biobehav Rev 79:27-47. https://doi.org/10.1016/j.neubiorev.2017.05.003

14. Mandell DM, Han JS, Poublanc J, Crawley AP, Stainsby JA, Fisher JA, Mikulis DJ (2008) Mapping cerebrovascular reactivity using blood oxygen level-dependent MRI in patients with arterial steno-occlusive disease: comparison with arterial spin labeling MRI. Stroke 39:2021-2028. https://doi.org/10.1161/ strokeaha.107.506709

15. Fraga de Abreu VH, Peck KK, Petrovich-Brennan NM, Woo KM, Holodny AI (2016) Brain tumors: the influence of tumor type and routine MR imaging characteristics at BOLD functional MR imaging in the primary motor gyrus. Radiology 281:876-883. https:// doi.org/10.1148/radiol.2016151951

16. Stienen MN, Fierstra J, Pangalu A, Regli L, Bozinov O (2018) The Zurich checklist for safety in the intraoperative magnetic resonance imaging suite: technical note. Oper Neurosurg (Hagerstown). https://doi.org/10.1093/ons/opy205

17. Fierstra J, van Niftrik C, Piccirelli M, Bozinov O, Pangalu A, Krayenbuhl N, Valavanis A, Weller M, Regli L (2018) Diffuse gliomas exhibit whole brain impaired cerebrovascular reactivity. Magn Reson Imaging 45:78-83. https://doi.org/10.1016/j. mri.2017.09.017

18. van Niftrik CH, Piccirelli M, Bozinov O, Pangalu A, Valavanis A, Regli L, Fierstra J (2016) Fine tuning breath-hold-based cerebrovascular reactivity analysis models. Brain Behav 6:e00426. https:// doi.org/10.1002/brb3.426

19. van Niftrik CHB, Piccirelli M, Bozinov O, Pangalu A, Fisher JA, Valavanis A, Luft AR, Weller M, Regli L, Fierstra J (2017) Iterative analysis of cerebrovascular reactivity dynamic response by temporal decomposition. Brain Behav 7:e00705. https://doi.org/10.1002/ brb3.705

20. Muscas G, Bas van Niftrik CH, Fierstra J, Piccirelli M, Sebok M, Burkhardt JK, Valavanis A, Pangalu A, Regli L, Bozinov O (2019) Feasibility and safety of intraoperative BOLD functional MRI cerebrovascular reactivity to evaluate extracranial-to-intracranial bypass efficacy. Neurosurg Focus 46:E7. https://doi.org/10.3171/2018.11. FOCUS18502

21. Hsu YY, Chang CN, Jung SM, Lim KE, Huang JC, Fang SY, Liu HL (2004) Blood oxygenation level-dependent MRI of cerebral gliomas during breath holding. J Magn Reson Imaging 19:160-167. https://doi.org/10.1002/jmri.10447

22. Davis TL, Kwong KK, Weisskoff RM, Rosen BR (1998) Calibrated functional MRI: mapping the dynamics of oxidative metabolism. Proc Natl Acad Sci U S A 95:1834-1839

23. Fierstra J, Poublanc J, Han JS, Silver F, Tymianski M, Crawley AP, Fisher JA, Mikulis DJ (2010) Steal physiology is spatially associated with cortical thinning. J Neurol Neurosurg Psychiatry 81:290293. https://doi.org/10.1136/jnnp.2009.188078

24. Fisher JA (2016) The CO2 stimulus for cerebrovascular reactivity: fixing inspired concentrations vs. targeting end-tidal partial pressures. J Cereb Blood Flow Metab 36:1004-1011. https://doi.org/10 $.1177 / 0271678 X 16639326$

25. Carrera E, Kurtz P, Badjatia N, Fernandez L, Claassen J, Lee K, Schmidt JM, Connolly ES, Marshall RS, Mayer SA (2010) Cerebrovascular carbon dioxide reactivity and delayed cerebral ischemia after subarachnoid hemorrhage. Arch Neurol 67:434-439. https://doi.org/10.1001/archneurol.2010.43

Open Access This chapter is licensed under the terms of the Creative Commons Attribution 4.0 International License (http://creativecommons. org/licenses/by/4.0/), which permits use, sharing, adaptation, distribution and reproduction in any medium or format, as long as you give appropriate credit to the original author(s) and the source, provide a link to the Creative Commons license and indicate if changes were made.

The images or other third party material in this chapter are included in the chapter's Creative Commons license, unless indicated otherwise in a credit line to the material. If material is not included in the chapter's Creative Commons license and your intended use is not permitted by statutory regulation or exceeds the permitted use, you will need to obtain permission directly from the copyright holder. 